\title{
Shallow landslide full-scale experiments in combination with testing of a flexible barrier
}

\author{
L. Bugnion ${ }^{1} \&$ C. Wendeler ${ }^{2}$ \\ ${ }^{1}$ Swiss Federal Institute for Forest, \\ Snow and Landscape Research WSL, Switzerland \\ ${ }^{2}$ Geobrugg AG, Switzerland
}

\begin{abstract}
Open shallow landslides occur regularly in a wide range of natural terrains. Generally, they are difficult to predict and result in damages to properties and disruption of transportation systems.

In order to improve the knowledge about the physical process itself and to develop new protection measures, full-scale experiments were conducted in Veltheim, Switzerland. Material was released down a test slope into a flexible barrier. The flow, as well as the impact into the barrier, was monitored using various measurement techniques. Laser devices recording flow heights and a special force plate measuring normal and shear basal forces, as well as load cells for impact pressures, were installed along the test slope. In addition, load cells were built in the support ropes and retaining cables of the barrier to provide data for detailed back-calculation of load distribution during impact. A release mechanism simulating the sudden failure of the slope was designed such that about $60 \mathrm{~m}^{3}$ of mixed earth and gravel saturated with water can be released in an instant.

The analysis of cable forces coupled with impact pressures and velocity measurements during a testing series now allows one to develop a load model for the barrier design. The first numerical simulations of the impacted barrier lead to structural improvements of new protection measures. It appears that special adaptations to the system, such as smaller mesh sizes, a special ground-barrier interface compared to normal rock-fall barriers and channelized debris flow barriers, are necessary in order to improve the retention capacity of shallow landslide barriers.
\end{abstract}


Detailed analysis of the friction coefficient in relationship with pore water pressure measurements gives interesting insights into the dynamic of fluid-solid mixed flows. Impact pressure dependencies on flow features are analyzed and discussed with respect to existing models and guidelines for shallow landslides. Keywords: shallow landslide, basal forces, impact pressure, protection barrier.

\section{Introduction}

Landslides are gravity driven flows including rock fall, debris-flow, deep-seated landslide and shallow landslide. Shallow landslide refers to slope failure with a depth of the sliding surface up to $2 \mathrm{~m}$ [1]. They can mobilize up to $200 \mathrm{~m}^{3}$ of water saturated soil material and debris. Most of the time they take place during heavy rainfall, thus their initiation is very much influenced by the structure and composition of the soil layers. Typically the presence of low permeability bedrock close to the ground surface enhances the risk of failure. The vegetation type and distribution within the soil layer will also play an important role in the stability of the slope [2].

In contrary to deep-seated landslides that are principally slow and creeping mass movements, shallow landslides release and come to a rest within tens of seconds. They are quite unpredictable and no measures can be taken during their occurrence. In spite of their limited volume compared to other phenomenon like debris-flows they can be very destructive due to their high bulk density of and to large front velocities. Habitations, roads and railway lines in the vicinity of steep terrain are primarily concerned with the shallow landslide hazard.

Up to now abundant research was done on the shallow landslide phenomena addressing various aspects of the initiation and flowing processes. The presence of pore water in the ground was studied regarding soil permeability, soil porosity and flow rates. Concepts like pore water pressure, soil suction and effective normal stress were introduced to assess the stability of slopes [3-5].

Many efforts were made to understand the rheology of landslide material and processes that condition the ability of the material to flow. The complexity of material made of particles from $\mu \mathrm{m}$ sizes like clays up to $\mathrm{cm}$ sizes like gravel passing over silt and sand made the task very difficult. Laboratory works including triaxial compression tests, rotating drum and small-scale chute experiments [6] were carried out in order to define viscosities and yield stresses values. However the application of results obtained in laboratory for the modelling of full-scale flows turns out to be thoughtful.

The lack of data on shallow landslides motivated the present project. The goal consisted in gathering information on full-scale shallow landslides. Flow features were to be acquired under controlled conditions in a repeatable way. The release of material down a slope makes up a good solution as long as the material composition and released volume are representative for shallow landslides.

The second goal was to investigate the impact of shallow landslides with flexible protection barriers. The measurements obtained were to allow refining and calibration of load models used in this field. 


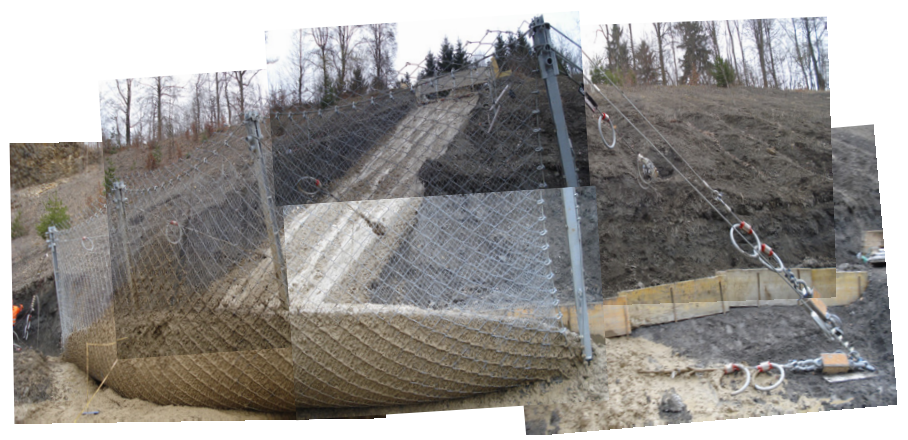

Figure 1: $\quad$ Test site with filled barrier, lower and upper support ropes with built in brake rings and force cells.
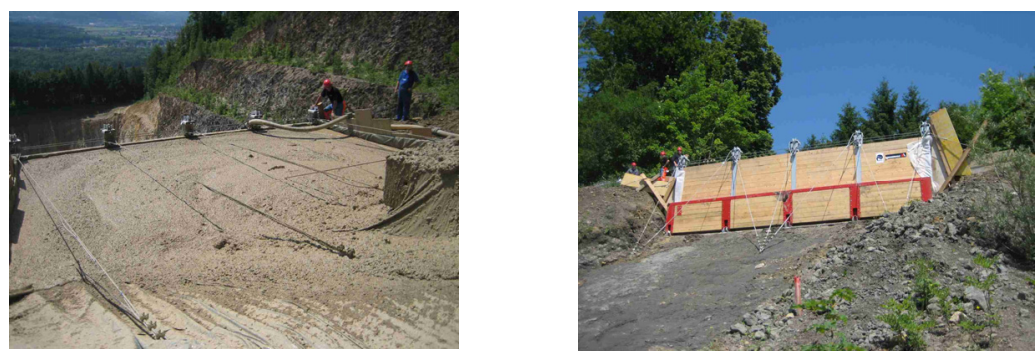

Figure 2: $\quad$ Filled release apparatus and trap door.

\section{Test site}

The selected testing site is a disused quarry located in the Veltheim community in the canton Aargau (Switzerland). The test slope is an $8 \mathrm{~m}$ wide and 41 long channel with an average inclination of $30^{\circ}$. The sides of the channel are about 1 $\mathrm{m}$ high and the bed surface is made of bedrock covered by sediments. At the top of the slope a release apparatus was built. It consists in a $1.8 \mathrm{~m}$ high wall whose $0.8 \mathrm{~m}$ lower section is a trap door that can be opened per distance. The lateral sides as well as the bottom surface above the wall are reinforced and made impermeable. The release apparatus has a capacity up to $50 \mathrm{~m}^{3}$ material.

The landslide material is prepared by a digger out of earth material and gravel. The largest cobbles have a size up to $20 \mathrm{~cm}$. Water is added until saturation and the whole is stirred up into a homogenous mixture. The material is then transported per truck and poured into the reservoir. The duration between material mixture and release lasts between 2 to 3 hours preventing material sedimentation in the release apparatus.

The flexible barrier is installed at the end of the $40 \mathrm{~m}$ long channel. It consists of three fields between the posts with a maximum span width of $5 \mathrm{~m}$. The $3.5 \mathrm{~m}$ high posts are hold upslope with retaining cables. From post to post support ropes at the top and bottom hold the SPIDER wire mesh. This wire mesh consists 

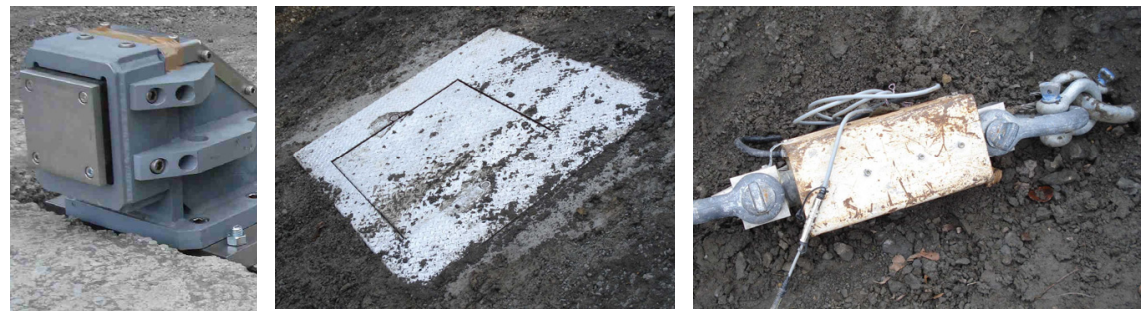

Figure 3: Impact pressure sensor, force plate and force cell.

of high tensile wire with mesh sizes of $130 \mathrm{~mm}$ that holds back most of the largest particles. Additionally a second layer of a chain-link mesh with smaller meshes prevents large draining of finer material. All support ropes are equipped with brake elements which get elongated under increasing load level.

\subsection{Measurement devices}

The main goals of the instrumentation and data acquisition on the Veltheim test site were on the one hand to quantify the full-scale shallow landslides in terms of velocities, flow heights, impact pressure and basal forces, on the other hand to measure the loading and deformation of the flexible barrier under impact. Several measurement devices were installed along the channel or built in the flexible barrier.

Laser distance sensors were located $14 \mathrm{~m}$ and $26 \mathrm{~m}$ downward from the release apparatus. At the second location, 2 distance sensors were placed next to each other in order to obtain 2 similar signals slightly shifted in time.

A square-shaped force plate with $0.5 \mathrm{~m}^{2}$ surface was mounted in the channel bed surface $26 \mathrm{~m}$ downward from the release apparatus (location 2 of distance sensor). It measures shear and normal basal forces at the flow bottom. The force plate was enclosed in a $2 \mathrm{~m} \times 1.5 \mathrm{~m}$ concrete foundation built flush to the channel bed surface.

Impact pressures are measured $30 \mathrm{~m}$ downward from the release apparatus. Two obstacles with $12 \mathrm{~cm} \mathrm{x} 12 \mathrm{~cm}$ and $20 \mathrm{~cm}$ x $20 \mathrm{~cm}$ measuring surfaces were installed in the middle of the channel. The heights of the obstacles are respectively $18 \mathrm{~cm}$ and $26 \mathrm{~cm}$.

A total of 4 force cells were built in the barrier upper and lower support ropes as well as in 2 retaining cables. They can measure forces up to $200 \mathrm{kN}$. After the release the filled barrier is measured using a tachometer. Single mesh nodes, shackles and posts are recorded with $3 \mathrm{D}$ coordinates.

All the data from the measurement devices were recorded with $2 \mathrm{kHz}$ acquisition rate. The results in section 3 are smoothed with a moving average method over $0.1 \mathrm{~s}$ time intervals.

\section{Results}

In this section, the results from 6 experiments conducted between September 2008 and October 2009 are presented with release of $50 \mathrm{~m}^{3}$ material. Not all 
Table 1: $\quad$ Summary of experiments $\# 2$ to \#8.

\begin{tabular}{|c|c|c|c|c|c|}
\hline Experiment & $\begin{array}{c}\text { Mean velocity } \\
\text { (front velocity at } \\
\text { location 1/2) (m/s) }\end{array}$ & $\begin{array}{c}\text { Maximum } \\
\text { flow height at } \\
\text { location 2 } \\
(\mathrm{m})\end{array}$ & $\begin{array}{c}\text { Density } \\
\left(\mathrm{kg} / \mathrm{m}^{3}\right)\end{array}$ & $\begin{array}{c}\text { Water } \\
\text { content }(\% \\
\text { of mass) }\end{array}$ & $\begin{array}{c}\text { Main } \\
\text { component }\end{array}$ \\
\hline$\# 2$ & $9.5(9 / 11)$ & 0.4 & 1900 & 14 & Gravel \\
\hline$\# 4$ & $6.9(8.6 / 6.1)$ & 0.5 & 1850 & 22 & Sand + fines \\
\hline$\# 5$ & $8.7(8.9 / 9.1)$ & 0.35 & 1920 & 21 & $\begin{array}{c}\text { Gravel }+ \\
\text { sand }\end{array}$ \\
\hline$\# 7$ & $9.8(9.1 / 11.1)$ & 0.3 & 1760 & 17 & Gravel +Sand \\
\hline$\# 77$ & $9.5(10 / 11.1)$ & 0.3 & 1760 & 17 & Gravel +Sand \\
\hline$\# 8$ & $7.9(8.3 / 8.3)$ & 0.35 & 1840 & 25 & Sand + fines \\
\hline
\end{tabular}

devices were installed or worked properly at the time of the experiments so that the data available varies from one experiment to another.

The mean velocity and the amount of deposited material were not only dependant on the material composition but also on the channel bed surface. If the channel was dry and covered with sediments like in experiment \#4 the flow was slower and large amount of material deposited. If the bed surface was wet or covered with little sediment the flow was faster and little material deposited.

\subsection{Flow heights}

The flow heights at location 1 and 2 are plotted in Figure 4. As a first remark maximum flow heights are larger for slower flow with same starting volume. The maximum flow heights decrease between location 1 and 2 when the flow front is accelerating (experiments $\# 2, \# 5$ and $\# 7$ ) and increase when the flow front decelerates (experiment \#4). It shows that the flow is either spreading (maximum acceleration at the front) or compacting (minimum acceleration at the front). This interpretation of the flow height changes is consistent with the flow surface velocities and friction coefficients discussed in section 3.2 and 3.3.

In addition to the deformation of the bulk (spreading or compaction), material deposition takes place all along the channel. The deposit heights measured at location 1 and 2 vary between 5 and $25 \mathrm{~cm}$. If the flow velocities over time at location 1 and 2 were known it would be possible to integrate the volume of material passing by and though quantifying the volume of the material deposited between location 1 and 2 . In the present case only qualitative flow surface velocities over time are available (see section 3.2) so that it is not done. But an interesting feature of the deposition process can be observed when considering the passing time of the flow tail at location 1 and 2. The passing times coincide approximately indicating that material is coming to a rest at location 1 and probably also at location 2 Otherwise it would mean that the tail is infinitely fast between location 1 and 2 . We conclude that material deposits continuously at the tail. The depositing at the tail can be recognized when looking at the basal force measurements in section 3.3. 

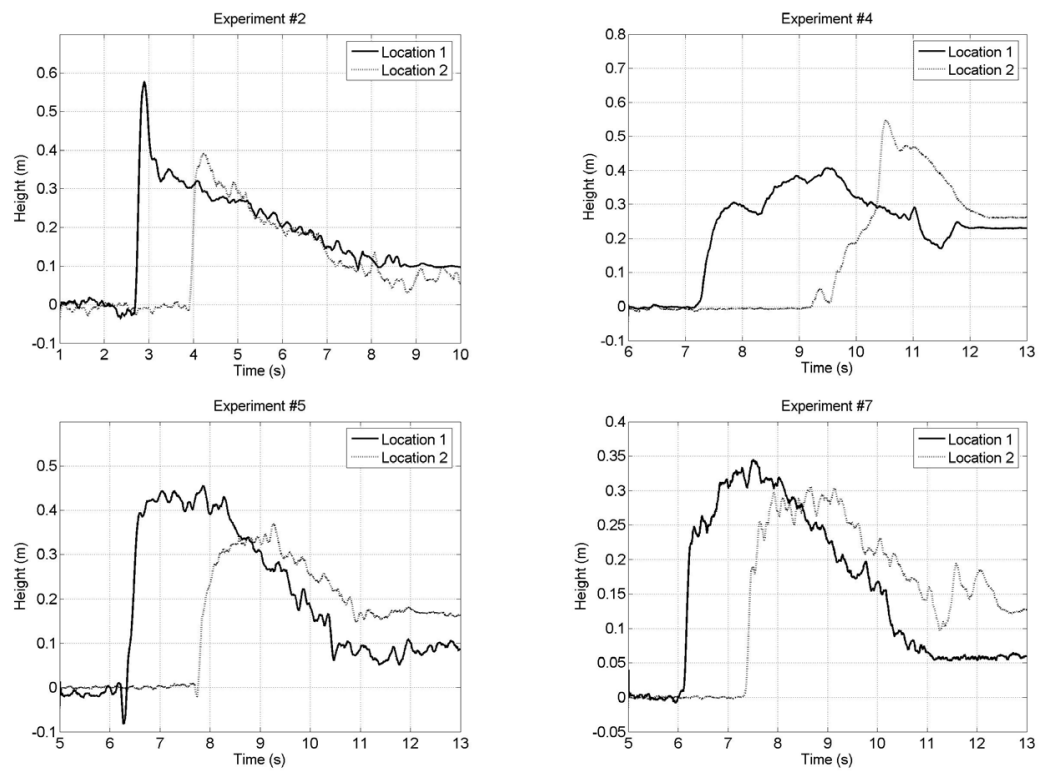

Figure 4: $\quad$ Flow heights versus time at locations 1 and 2 for experiments \#2, $\# 4$, \#5 and \#7.

\subsection{Flow surface velocities}

The flow front velocities are easily determined from camera recordings or from the flow height measurements. Thus they provide no information about the deformation of the flowing material or about the accelerations of the rest of the flow. Flow surface velocities over time were estimated by cross-correlating 2 flow height signals recorded at location 2 . The 2 distance sensors were set up next to each other with $3.5 \mathrm{~cm}$ distance between them. The discrete crosscorrelation function used was the following:

$$
h_{1} h_{2}(t, \Delta t)=\sum_{t^{\prime}=t-b i n_{-} \text {size }}^{t+\text { bin_size }} \frac{h_{1}\left(t^{\prime}\right)-\bar{h}_{1}}{\sigma_{h 1}} \frac{h_{2}\left(t^{\prime}+\Delta t\right)-\bar{h}_{2}}{\sigma_{h 2}}
$$

where $\bar{h}_{i}$ is the mean value of $h_{i}$ and $\sigma_{h i}$ the standard deviation of $h_{i}$ over the interval $\left[t-b i n_{-}\right.$size, $t+b_{\text {in }}$ size $]$. The time delay at time $t$ between the 2 flow height signals is the time interval $\Delta t$ that maximizes the crosscorrelation function $h_{1} h_{2}(t, \Delta t)$.

The results for the flow surface velocities are plotted in Figure 5. The calculation was done for flows that were spreading. Consistently all flow surface velocities obtained all show a monotonous decrease from front to tail. No more precise conclusion can be made even if the decrease seems to be more pronounced in the tail. 

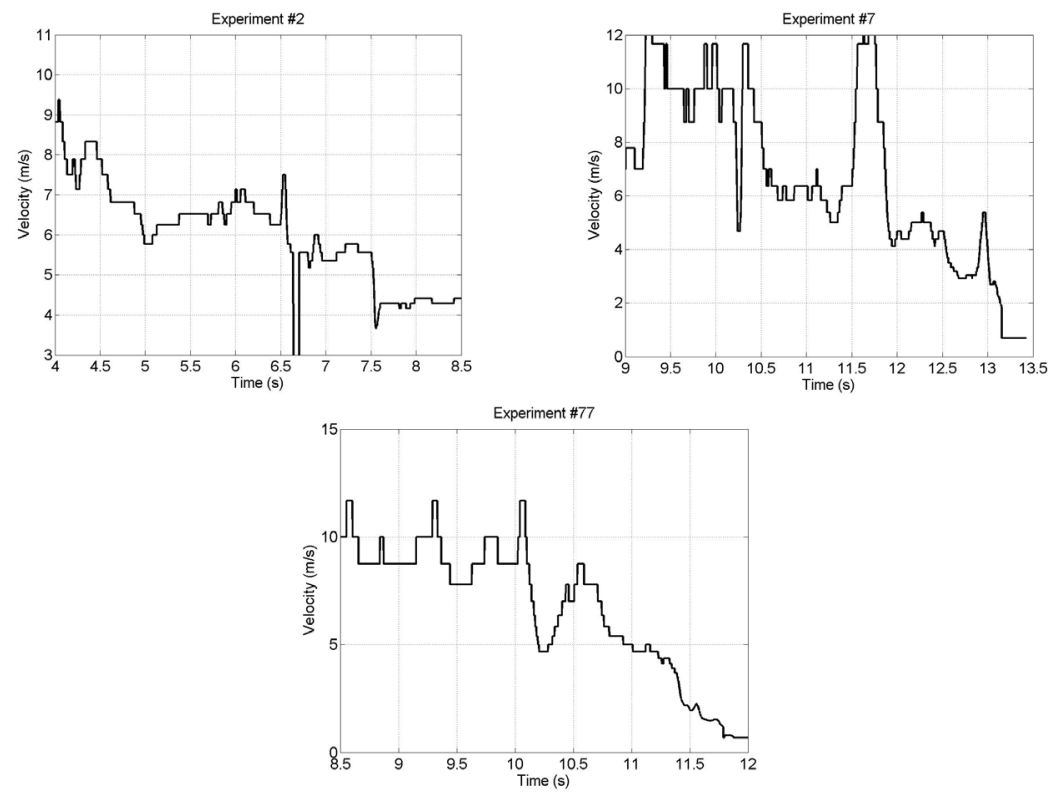

Figure 5: $\quad$ Flow surface velocities versus time for experiments \#2, \#7 and \#77.
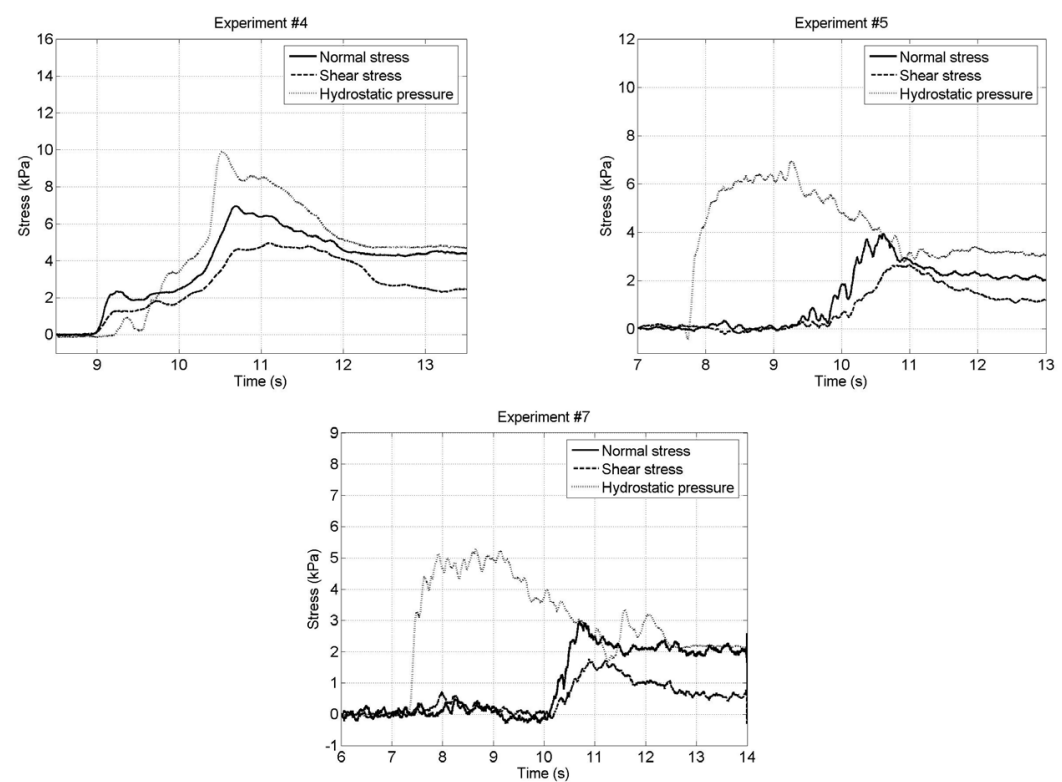

Figure 6: Basal stresses and hydrostatic pressure versus time for experiments \#4, \#5 and \#7. 


\subsection{Basal forces}

Normal and shear forces were measured over time with the force plate. They are represented in Figure 6 for experiments \#4, \#5 and \#7. In the case of fast flows the problem arose that material was deflected before the force plate due to a slightly lower inclination at this location. The problem was less pronounced in the case of slower flows and inexistent for slow flow like experiment \#4. The correspondence between hydrostatic pressure computed from the flow height measurements and the normal force is satisfying although the normal forces are often slightly lower. Discrepancies can be explained by the fact that laser distance sensors measure the flow height over a $0.2 \mathrm{~cm}^{2}$ surface while the force is measured over a $0.5 \mathrm{~m}^{2}$ surface.

Taking the ratio of the shear force to normal force gives the friction coefficient that is plotted in Figure 7. Except for experiment \#4 where the friction coefficient is available over the whole flow, friction coefficient values are principally obtained for the flow bulk and tail. In the front and in the bulk the friction coefficient is higher than the tangent of the slope angle for compacting flow (experiment \#4) and lower for spreading flows (experiment \#5 and \#7). For all experiments the highest friction coefficient values are attained in the end of the tail just before the flow height gets to a constant value (deposit height). Only then the friction coefficient value decreases to the tangent value corresponding to the equilibrium of the immobile deposit. The friction coefficient high values at the end of the tail suggest that the material is depositing over the force plate and
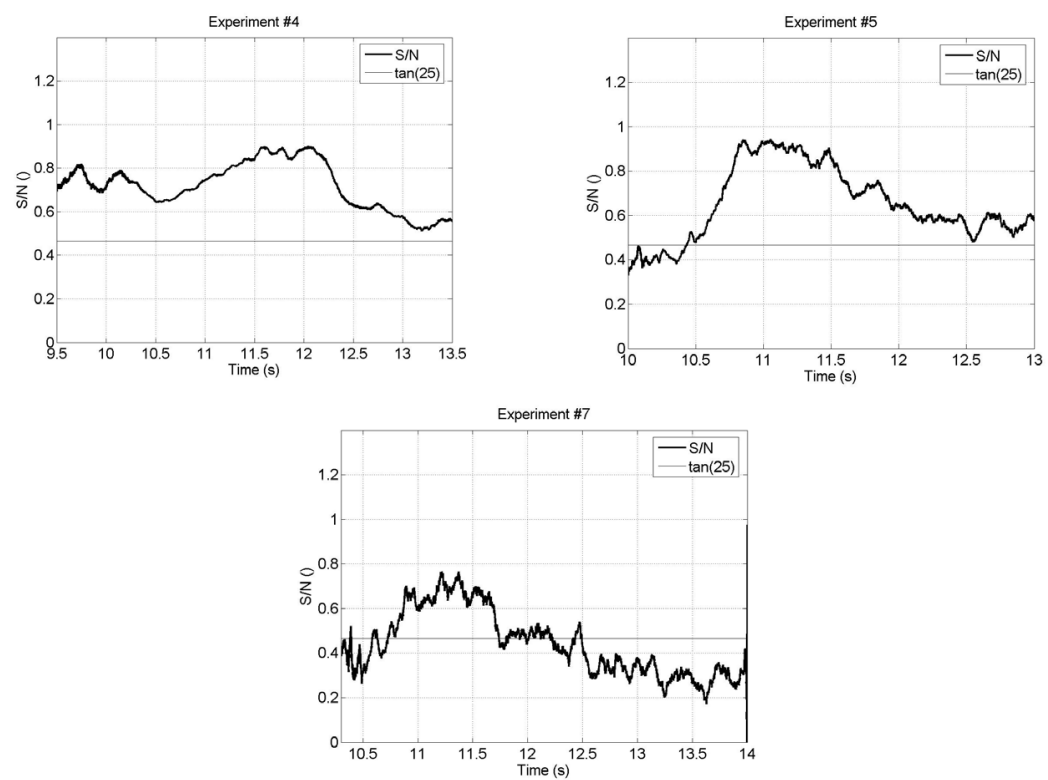

Figure 7: $\quad$ Friction coefficient versus time for experiments \#4, \#5 and \#7. 

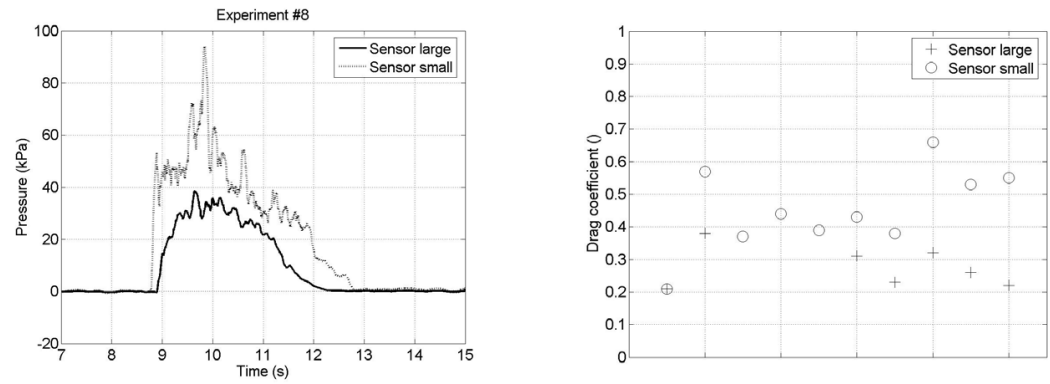

Figure 8: Impact pressures for experiment \#8 and drag coefficients for experiments \#4 to \#8.

not just flowing past. What makes the flow stop at the end of the tail and not in the front can be due to the small flow heights at the end of the tail that would not be able to compensate some basal friction or material yield stress.

\subsection{Impact pressure}

Impact pressures were measured $4 \mathrm{~m}$ downward from the force plate. An ideal dynamic pressure measurement is not supposed to disturb the flow. In the present case the obstacle size has the same order of magnitude as the flow height. The flow was therefore deviated over and on the sides of the obstacle.

Assuming the impact pressure proportional to the material density and the impact velocity square the drag coefficient $\mathrm{c}_{\mathrm{w}}$ is defined (see (2)). In Figure 8 the drag coefficient is calculated at the flow front for experiments \#4 to \#8.

$$
c_{w}=\frac{P}{\rho v^{2}}
$$

The smaller cell measures because of size effects due to particle sizes higher impact pressures leading to higher drag coefficients (see Table 2).

For further investigations of the impact pressure exerted on the barrier the values of the larger load cell are considered which seems to be more reasonable.

\subsection{Interaction shallow landslide impact - flexible ring net barrier}

A particular ground adaptation is necessary for the flexible shallow landslide barriers compared to the flexible debris flow barriers having a special basal opening (see Figure 9, [7]). This mesh fixed to the ground helps keeping the lower support rope to the bottom during the impact [8]. Hence also flows with small flow heights can completely be stopped and only the not innocuous liquid is able to pass through the mesh.

After 8 tests with varied mixtures, partly with several releases, we are able to present the following results for barrier design. First calculations of barrier design are given in [8]. Most important load case for barrier design is the 
dynamic impact of the surge and the static load case for the expected filling height.

With the measured drag coefficient for each test the intensity of the flow hitting the barrier can be estimated. For an engineering approach we assume the flow acts equally over the channel width to the bottom support rope (see Figure $10,[7])$.

Assuming a constant pressure acting to the middle field and to one third of each border field (see Figure 10) the following load distribution to lower support rope can be done. The middle part of the rope is hit by the pressure q1 depending

Table 2: $\quad$ Drag coefficients for experiments \#4 to \#8.

\begin{tabular}{|l|c|c|}
\hline Experiment & $\begin{array}{l}\mathrm{c}_{\mathrm{w}} \text { small cell () } \\
\text { first/second shot }\end{array}$ & $\begin{array}{l}\mathrm{c}_{\mathrm{w}} \text { big cell () } \\
\text { first/second shot }\end{array}$ \\
\hline$\# 4$ & 0.21 & 0.21 \\
\hline$\# 5$ & 0.57 & 0.38 \\
\hline$\# 6$ & 0.37 & - \\
\hline$\# 7 / \# 77$ & $0.44 / 0.39$ & $-/-$ \\
\hline$\# 8 / \# 88$ & $0.43 / 0.38$ & $0.31 / 0.23$ \\
\hline
\end{tabular}
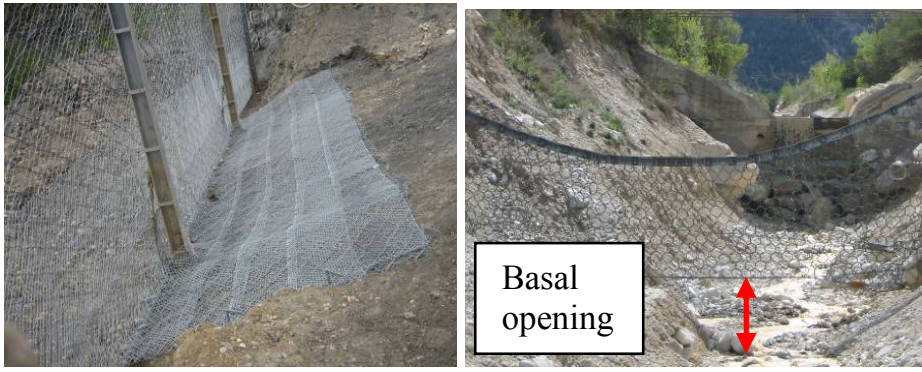

Figure 9: Particular ground adaptation with a fixed mesh for shallow landslide barriers (left) and extra projected basal openings for debris flow barriers (right).

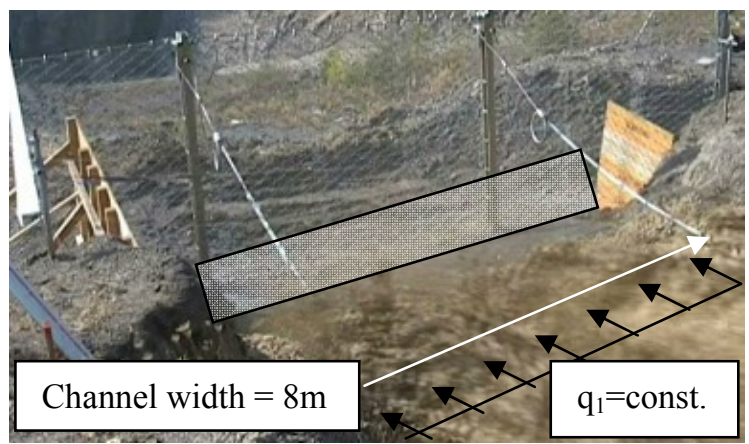

Figure 10: Impacted area on the flexible barrier and assumed constant pressure distribution in the middle field. 


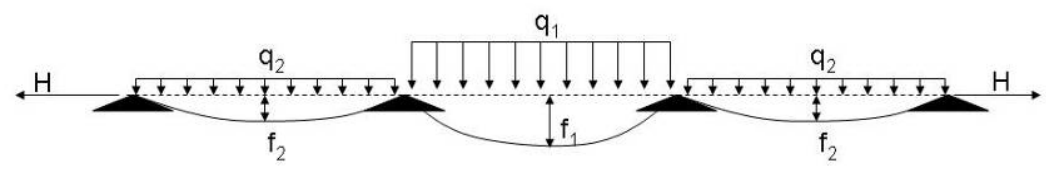

Figure 11: Simplified rope distribution to a three field supported rope.

on the flow velocity $\mathrm{v}$ squared, the density and the flow height given in [7]. In the border field in reality only one third of the span width is affected by the flow. This effect is considered approximately by assuming the pressure $\mathrm{q} 1$ over the influenced length and transferring it to the complete span width to $\mathrm{q} 2$ by $\mathrm{q}_{2}=\mathrm{q}_{1} / 3$. This method allows us a simplified solution by Newton iteration of the rope equation (see (3)).

$$
H^{3}+H^{2} \cdot E A \cdot\left[1-\frac{1}{s_{0}} \cdot l\right]=\frac{E A}{2 S_{0}}\left(\int_{0}^{l_{1}} Q_{1} d x+\int_{0}^{l_{2}} Q_{2} d x+\int_{0}^{l_{3}} Q_{3} d x\right)
$$

with $\int Q_{i}=\frac{q_{i}^{2} \cdot l_{i}^{3}}{12}$

In this assumption $\mathrm{q}_{2}$ and $\mathrm{q}_{3}$ are in the same order of magnitude (see Figure 11).

Last test performed without the mesh adaptation at bottom support ropes was test number three. Running back calculation of Test number three we can proof this rope equation approach without having an additional force component going into the fixed mesh to the ground. For experiment \#3 we assume a drag coefficient of 0.3 which is a middle value of the measured values of experiments \#4 to \#8 for big cell (see Table 2). The observed flow height of experiment \#3 close to the barrier was $0.15 \mathrm{~m}$, the middle front velocity $11 \mathrm{~m} / \mathrm{s}$ with a flow density of $2050 \mathrm{~kg} / \mathrm{m}^{3}$. This results into a maximum dynamic pressure of $\mathrm{q}_{1}=0.15 \cdot 2050 \cdot 0.32 \cdot 11^{2}=11.9 \mathrm{kN} / \mathrm{m}$ in the middle field. The border fields were loaded with $\mathrm{q}_{2}=3.6 \mathrm{kN} / \mathrm{m}$. No brake ring deformation was observed. The rope equation leads to a rope force of $98 \mathrm{kN}$ whereas the measured rope force was 110 $\mathrm{kN}$. With $10 \%$ deviation the rope equation approach fits the measured rope forces. This allows us to estimate the force transmitted by the additional fix point of mesh to the ground. The calculations showed us, that the impact pressure is transmitted in the following experiments $\# 4$ to $\# 8$ half to the ground adaptation and half by the lower support ropes (see Table 3 ).

In four times we underestimate the measured rope force of bottom rope with maximum $8 \%$ of deviation. One experiment, $\# 5$, we overestimate the rope force with this approach. The explanation for the overestimation in experiment \#5 can be a tighter installed mesh to the ground or a fault in drag coefficient or velocity values.

Of course this solution fits only for the first impact to net to lower support ropes. But the upper support ropes had always a similar load distribution mostly with a peak load of $10 \%$ lower than the bottom support ropes (see Figure 12). For the peak forces of retaining ropes the second, third release is decisive and of course the hydrostatic pressure of material behind the barrier [8]. 
Table 3: Comparison of the solution of the rope equation with measured rope force.

\begin{tabular}{|c|c|c|c|c|}
\hline Experiment & $\begin{array}{c}\text { Impact to middle } \\
\text { field }(\mathrm{kN} / \mathrm{m})\end{array}$ & $\begin{array}{c}\text { Solution of rope } \\
\text { equation }(\mathrm{kN})\end{array}$ & $\begin{array}{c}\text { Measured rope } \\
\text { force }(\mathrm{kN})\end{array}$ & Deviation (\%) \\
\hline$\# 4$ & 1.8 & 11 & 12 & -8.0 \\
\hline$\# 5$ & 16.6 & 76 & 79 & -3.7 \\
\hline$\# 6$ & 36.5 & 116 & 98 & +18.0 \\
\hline$\# 7$ & 17.0 & 83 & 85 & -2.3 \\
\hline$\# 8$ & 10.6 & 53 & 55 & -3.6 \\
\hline
\end{tabular}

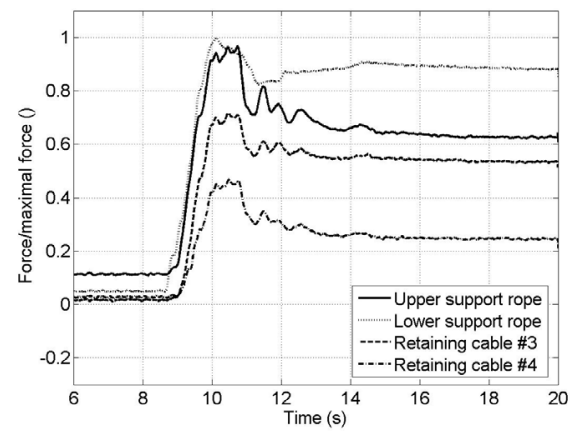

Figure 12: Force to maximal force ratio versus time in the upper and lower support ropes and in retaining cables \#3 and \#4.

\section{Conclusions}

The results of full-scale shallow landslide experiments are presented. $50 \mathrm{~m}^{3}$ of landslide were released on a $40 \mathrm{~m}$ long and $8 \mathrm{~m}$ wide channel with $30^{\circ}$ inclination. The material was made of gravel, sand and clay saturated with water. Flow heights, basal stresses, front velocities and surface velocities were measured. At the end of the test slope a flexible barrier with high tensile steel net installed. Forces in the support ropes and retaining cables were recorded during impact.

The flow height measurements allowed the distinction between spreading and compacting flows. The time interval between the passing time of the tail ends suggested that material is deposited continuously at the tail end. Crosscorrelation of flow height signals showed monotonous decrease in the flow surface velocity for spreading flows. The analysis of basal stresses revealed a systematic maximum of the friction coefficient in the tail end consistently with the interpretation of the flow height measurement. The friction coefficient values in the front and in the bulk depend to a large extent on the bed surface friction properties.

A method was developed to estimate the maximum dynamic load in the barrier during impact of the flow. By assuming constant drag coefficient over the channel width the forces in the lower support rope were calculated and compared 
with the measured forces solving the rope equation. The effect of the ground adaptation was also estimated.

\section{References}

[1] Kantonale Gebäudeversicherungen (2005), Objektschutz Rutschungen.

[2] Schwarz M. (2008), Characterization of the vegetation cover at the test site of Rüdlingen, Internal CCES-TRAMM report.

[3] Terzaghi K. (1925), Erdbaumechanik, Franz Deutike, Vienna.

[4] Iverson R.M. (1997), The physics of debris-flows, Reviews of Geophysics, 35, 245-296.

[5] Springman S. et al. (2009), Landslide triggering experiment in a steep forested slope in Switzerland, Proceedings of the 17th International Conference on Soil Mechanics and Geotechnical Engineering, doi:10.3233/978-1-60750-031-5-1698.

[6] Iverson R. M. et al. (2009), The Perfect Debris Flow? Aggregated Results from 28 Large-scale Experiments, submitted.

[7] Wendeler C. et al. (2010), Structural design of flexible steel barriers for torrent debris flow mitigation, in preparation.

[8] Bugnion L. et al. (2008), Versuche zum Rückhalt von oberflàchennahen Rutschungen mit flexible Schutznetzen. Proceedings of the Christian Veder Kolloquium 